\section{AB023. An atypical clinical presentation of alopecia in two patients with systemic lupus erythematosus}

\author{
Irina Lerman ${ }^{1}$, Ritesh Agnihothri ${ }^{2}$, \\ Glynis A. Scott ${ }^{2}$, Christopher T. Richardson ${ }^{2,3}$ \\ ${ }^{1}$ University of Rochester School of Medicine and Dentistry, \\ Rochester, NY, USA; ${ }^{2}$ Department of Dermatology, University of \\ Rochester Medical Center, Rochester, NY, USA; ${ }^{3}$ Division of Allergy, \\ Immunology and Rheumatology, University of Rochester Medical \\ Center, Rochester, NY, USA \\ Correspondence to: Christopher T. Richardson. Department of \\ Dermatology, URMC, 601 Elmwood Ave., Box 697, Rochester NY \\ 14642, USA. Email: crichardson@urmc.rochester.edu.
}

\begin{abstract}
Alopecia in varying patterns is a common feature of lupus erythematosus (LE). Several forms of alopecia that are not specific to LE can occur in the setting of lupus, such as alopecia areata, telogen effluvium, and anagen effluvium. LE-specific alopecias are defined as those with histology consistent with LE, and include forms of acute, subacute, and chronic cutaneous lupus erythematosus (CCLE). Common patterns of LE-specific alopecia include the nonscarring diffuse hair thinning and fragility of acute LE and the scarring, erythematous scaly plaques with follicular keratotic plugs, peripheral hyperpigmentation, and central hypopigmentation of discoid lupus erythematosus (DLE). Lupus erythematosus tumidus (LET) may also present on the scalp as well-defined, non-scarring alopecia without overlying scale, atrophy, and dyspigmentation. We report two male patients with large circular non-scarring alopecic
\end{abstract}

plaques on the scalp without overlying scale or erythema, but with central hyperpigmentation and scarring - findings reminiscent of but also distinct from both DLE and LET. Punch biopsy from the hyperpigmented area of alopecia revealed peri-follicular lymphocytic infiltrate, follicular dropout, and increased dermal mucin consistent with LE; further workup and serologic testing revealed systemic lupus in both patients. These two cases demonstrate a unique clinical presentation of central scarring alopecia within a larger non-scarring alopecic plaque in the setting of SLE that deviates from typical lupus-related alopecia. Teaching point: these two cases underscore the morphologic heterogeneity of CCLE and need for thorough evaluation of systemic disease in patients presenting with both scarring and non-scarring alopecia.

Keywords: Alopecia; chronic cutaneous lupus erythematosus (CCLE); discoid lupus erythematosus (DLE); lupus erythematosus tumidus (LET); systemic lupus erythematosus (SLE)

doi: 10.21037/atm.2021.AB023

Open Access Statement: This is an Open Access article distributed in accordance with the Creative Commons Attribution-NonCommercial-NoDerivs 4.0 International License (CC BY-NC-ND 4.0), which permits the noncommercial replication and distribution of the article with the strict proviso that no changes or edits are made and the original work is properly cited (including links to both the formal publication through the relevant DOI and the license). See: https://creativecommons.org/licenses/by-nc-nd/4.0/.

Cite this abstract as: Lerman I, Agnihothri R, Scott GA, Richardson CT. An atypical clinical presentation of alopecia in two patients with systemic lupus erythematosus. Ann Transl Med 2021;9(5):AB023. doi: 10.21037/atm.2021.AB023 